\title{
Aristóteles: educação moral e a formação do caráter
}

\author{
Rosane Rocha Viola Siquieroli*
}

Resumo: O presente artigo se propõe a apresentar uma visão a respeito das noções aristotélicas sobre a aquisição das virtudes morais e ainda estabelecer uma relação com a educação do caráter. Aristóteles atribui à habituação o papel de cultivar na alma humana a motivação para a ação correta. Num primeiro momento será discutido o papel das virtudes e em seguida será feita uma exposição sobre o método aristotélico de aquisição da virtude moral; tendo como resultado a criação e o desenvolvimento da virtude do caráter.

Palavras-chave: virtude do caráter, virtude moral, Aristóteles, educação moral.

\section{Aristotle: moral education and character formation}

\begin{abstract}
This article proposes to present a vision about the Aristotelian notions about the acquisition of the moral virtues and also to establish a relation with the education of the character. Aristotle attributes to habituation the role of cultivating in the human soul the motivation for right action. At first the role of the virtues will be discussed and then an exposition will be made on the Aristotelian method of acquisition of the moral virtue and having as a consequence the creation and the development of the virtue of the character.
\end{abstract}

Keywords: virtue of character, moral virtue, Aristotle, moral education.

\section{Introdução}

Este artigo se propõe a apresentar um aspecto da filosofia aristotélica que envolve ética, política e educação, especificamente a formação do caráter moral e a motivação moral nas ações virtuosas. A ética de Aristóteles reúne os ensinamentos para

\footnotetext{
* Mestranda em Filosofia da Universidade Federal de Uberlândia (UFU). E-mail: rosaneviola@gmail.com.
} 
a habilitação do homem tendo em vista a virtude moral e o cultivo do intelecto para o desenvolvimento da virtude intelectual, mas a finalidade aqui é analisar a primeira. $\mathrm{O}$ artigo baseia-se principalmente na Ethica Nicomachea e na Política, duas obras aristotélicas de capital importância para a compreensão do tema proposto.

O escopo da investigação consiste em elucidar o papel desempenhado pela virtude do caráter nas ações morais. Aristóteles nem sempre apresenta de forma clara e precisa o modo de aquisição das virtudes, abrindo espaço para inúmeras interpretações divergentes e polêmicas. Os problemas de natureza exegética, na medida em que são analisados, revelam como o filósofo se propunha a resolver as questões de filosofia moral que ele investigou em sua extensa obra.

\section{Posições conflituosas: a preponderância da razão}

É bem verdade que uma parcela significativa de estudiosos da ética de Aristóteles tem defendido um papel preponderante à razão na determinação dos fins morais pelo agente virtuoso. Aristóteles não garante em afirmações textuais que este papel incumbe à razão, sendo assim, uma investigação mais acurada dá conta de que existem evidências que elegem a virtude moral como a virtude par excellence responsável por determinar os fins morais. A atividade racional reflexiva é sem dúvida alguma fundamental para o exercício da ação virtuosa, isto porque Aristóteles determina que as ações virtuosas devem cumprir três condições: a ação virtuosa deve ser realizada intencionalmente, como fim em si mesma, e a ação virtuosa deve ser realizada a partir de um caráter firme e imutável (1105a 30-34). Mas estes são requisitos de uma ação virtuosa e não respondem completamente à questão de como se adquire a disposição virtuosa que possui a habilidade necessária para a prática de uma ação desta natureza. Ou seja, uma coisa é realizar uma ação correta e outra é ser genuinamente virtuoso e praticar uma ação correta.

O intelectualismo filosófico apresenta uma preocupação unilateral com a razão e o raciocínio, os defensores da supremacia da razão acreditam na necessidade incontestável da atividade racional em todo o âmbito da filosofia moral. Qualquer assunto relacionado ao tema é delimitado como o estudo do raciocínio moral, excluindo evidências importantes que sugerem algo mais abrangente no tocante ao 
desenvolvimento moral do homem. (BURNYEAT, 2012, p. 260) Aristóteles conhecia o intelectualismo na forma da doutrina de Sócrates que considerava a virtude como conhecimento. Mas a sua reação foi a de combater este ponto de vista, enfatizando a necessidade do desenvolvimento gradual dos bons hábitos no ser humano. A virtude moral aristotélica está relacionada diretamente com a criação de bons hábitos no agente e reivindica uma forma de educação apropriada. $\mathrm{O}$ 'homem bom' aristotélico nasce com a construção de uma hexis moral, ou seja, de uma disposição de caráter virtuosa. A prova cabal de que a virtude moral extrapola os limites do conhecimento é o homem acrático, aquele que conhece o bem, mas nem sempre o realiza em ação.

Usemos o rótulo 'intelectualistas' para aqueles que acreditam que Aristóteles garantiu a tarefa de fixar os fins morais não ao caráter, mas ao intelecto. Existem duas estratégias intelectualistas [...] uma é permitir que a virtude possua um papel crucial em nos fornecer os fins morais, enquanto insiste que ela o faz somente porque ela é em parte um estado intelectual. A outra é aceitar que a virtude é não-racional ao mesmo tempo que se nega que ela literalmente forneça nossos fins. (MOSS, 2011, p. 207)

Numa leitura mais superficial, a filosofia moral aristotélica, pode num primeiro momento, parecer contraditória. O processo de habituação para a aquisição das virtudes morais pode ensejar dúvidas, mas a contradição é apenas aparente se levarmos em consideração as informações dispersas principalmente na Ethica Nicomachea e na Política. Duas passagens de EN são utilizadas aqui no texto para demonstrar que Aristóteles defende a tese de que a virtude do caráter responde pelos fins da ação moral.

1. “[...] a virtude faz o alvo ser correto, ao passo que a sensatez faz ser correto o que leva ao alvo". (1144a 7-9)

2. “[...] o propósito correto não se pode dar sem sensatez nem sem virtude; uma nos faz fazer o fim, a outra leva a fazer as coisas que conduzem ao fim”. (1145a 4-6) ${ }^{1}$

\footnotetext{
${ }^{1}$ ANGIONI, 2011
} 
Ambas as passagens corroboram a tese de que os fins morais são responsabilidade da virtude do caráter e que Aristóteles delega à phronesis - traduzida como sensatez (ANGIONI) - apenas a atividade deliberativa sobre as coisas relativas ao fim. O filósofo restringe deste modo o alcance da jurisdição racional. Muito embora seja possível reunir evidências textuais, vários intérpretes se opõem à leitura de que Aristóteles não tenha garantido a supremacia da razão no tocante a escolha dos fins morais. Entre aqueles que defendem uma interpretação intelectualista da filosofia moral aristotélica se destacam Cooper, Hardie, Broadie, Mc Dowell, Greenwood e Joachim. Recentemente, Lorenz afirmou ser repulsivo que uma teoria negue que um bom caráter consista, em alguma medida, num bom entendimento dos assuntos humanos. (LORENZ, 2009, p. 178)

\section{Educação e formação moral}

Na Ethica Nicomachea livro II 1103a 14-20, Aristóteles diz que as virtudes são de dois tipos: intelectual e moral. A virtude intelectual deve seu nascimento e desenvolvimento ao ensino o que requer experiência e tempo, mas a virtude moral surge como resultado do 'hábito' - o próprio nome (etthikē) seria formado por uma ligeira variação da palavra grega 'ethos' que significa 'hábito' (1103a 14-20). No tocante à virtude moral, Aristóteles defende a tese de que elas não surgem no homem por natureza e afirma que nada que exista por natureza pode formar um hábito contrário à sua natureza (1103a1925).

A questão fundamental é compreender como Aristóteles entende que o engajamento no comportamento correto é capaz de desenvolver uma disposição virtuosa. A filosofia moral aristotélica nos revela que as virtudes se desenvolvem em nós em dois estágios distintos que são interdependentes, porque um não obtém sucesso sem a realização do outro: educação e ética estão intrinsecamente relacionadas na aquisição das virtudes. O primeiro estágio passa pela educação do caráter que demanda habituação e tempo e o segundo estágio exige o pleno desenvolvimento das habilidades racionais. Mas neste texto, o que nos interessa é a formação de um caráter virtuoso ou a formação do agente moral, tendo em vista a aquisição de virtude ainda no primeiro estágio. 
Em oposição às várias opiniões intelectualistas, filósofos contemporâneos defendem o método de aquisição das virtudes da maneira como Aristotéles o concebeu, mostrando que as convicções são formadas muito antes que alguém seja capaz de especificar o que, e se alguma coisa está errada.

\begin{abstract}
Aristóteles não poderia ter envolvido emoções em virtudes morais se não tivesse pressuposto a visão de que as emoções têm um componente cognitivo passível de avaliação racional e moral - e, se necessário (isto é, se não for irracionalmente formado e / ou moralmente injustificado), passível de crítica e mudança. Essa teoria cognitiva é, afinal de contas, a chave para o ideal fundamental da fusão do coração e da cabeça. O fato de que uma questão é emocionalmente carregada, decorrente do "coração", não significa que isso atrapalhe o governo da "cabeça"; em vez disso, os sentimentos podem ser propriamente pensativos, assim como os pensamentos podem ser sentidos adequadamente. Se eles são realmente ou não, é uma questão para investigação em cada caso particular; não há boa razão para uma rejeição das emoções como intrusos no reino da razão. (KRISTJÁNSSON, 2007, p. 18)
\end{abstract}

A educação do caráter, como método de aquisição das virtudes morais, é uma das tendências recentes mais proeminentes e está ancorada na teoria aristotélica. Os estudiosos defendem a necessidade da "inculcação,2 de bons hábitos na alma do aprendiz e consideram que nos estágios iniciais há a necessidade de mentores e exemplos morais.

Aristóteles é bem claro ao dizer que o desenvolvimento das virtudes deve se dar quando o homem é ainda jovem, caso contrário será tarde demais. A formação do caráter deve ser iniciada nos primeiros anos da juventude, nenhum tempo deve ser perdido antes que a inculcação dos bons hábitos comece (1103b 23-26). O treinamento moral deve ocorrer em parte por meio da habituação direta, as virtudes então, fixam-se na personalidade do aprendiz como a 'tintura na lã' .

A educação do caráter revela que não é suficiente tão somente o desenvolvimento de habilidades de raciocínio crítico nos jovens que há tempos era a ortodoxia dominante. Além disso, apresenta falhas - não conseguindo entregar o prêmio final da educação moral, que é tornar o homem bom, como salienta o filósofo da educação, Halstead McLaughlin.

\footnotetext{
${ }^{2}$ A palavra 'inculcação' é adotada neste texto, porque exprime bem o sentido desejado: gravar, imprimir algo na alma de alguém.
} 
A percepção de que o desenvolvimento moral e a educação moral requerem não apenas a conquista de certas capacidades cognitivas ou racionais por parte da pessoa, mas também o desenvolvimento de qualidades de caráter e virtude, é uma percepção que tem suas raízes em Platão e Aristóteles o que preocupou e confundiu filósofos desde então.(McLAUGHLIN, 2005, p.131)

A educação do caráter baseada na ética da virtude de Aristóteles é bastante promissora; alguns devotos de Aristóteles mantêm o foco na habituação como um método necessário de educação sociomoral, anterior ao aprimoramento do raciocínio crítico e da reflexão dos jovens. O treinamento do aprendiz moral é um processo complexo, primeiramente com a habituação na prática de ações corretas, até a formação do caráter, e depois desenvolvendo o entendimento progressivo das razões para agir. Em virtude da habituação nas ações morais, o agente é levado a sentir prazer na prática das ações corretas e a sentir incômodo na prática de ações incorretas. $\mathrm{O}$ objetivo e resultado final desse processo é chamado de 'virtude moral'. Somente mais tarde, o desenvolvimento do pensamento crítico no agente moral coroa de êxito a aquisição das virtudes éticas. Para Aristóteles, o conhecimento da virtude por si só, não é suficiente para determinar o comportamento humano. Fazem-se necessários esforços laboriosos para se atingir a excelência que o filósofo associa às virtudes, as noções de fazer e agir corretamente (1103b 29-32). Aristóteles não acredita que o ser humano é bom ou mau por natureza, mas que o homem nasce sem qualquer caráter (1103a 25-26).

No caso dos seres humanos normais, ou seja, daqueles que não são naturalmente incapacitados, fica a cargo exclusivamente da educação que se recebe o desenvolvimento de um caráter bom ou ruim. Aristóteles afirma na EN livro X 1179 b 20-30 que as opiniões a respeito deste assunto divergem; alguns acreditam que a hereditariedade determina o caráter do homem, outros defendem a habituação como único caminho para moldar o ser humano virtuoso e ainda há quem considere o ensino o mais eficaz. O filósofo que mostrou compreender como ninguém a natureza humana não acredita que o caráter humano seja uma dádiva da natureza, descarta esta possibilidade como causa da virtude moral. Ele também não crê no poder dos argumentos para criar a virtude no homem e então defende como único meio o cultivo de bons hábitos na alma do estudante, o que seria então a maneira eficiente para moldar o bom caráter, a prática repetida de atos virtuosos. Para o filósofo, a alma do estudante deve primeiro ter sido cultivada com hábitos nobres para que ele então torne-se 
virtuoso, assim como a terra deve ser cultivada para receber e nutrir a semente. Em 1179b24-26 afirma que: “[...] mas a alma do estudante deve primeiro ter sido cultivada por meio de hábitos para o nobre prazer e nobre aversão, como a terra para nutrir a semente."

Aristóteles é um árduo defensor da prática nas questões éticas; ele compara à aquisição de um bom caráter à aquisição de uma habilidade. Faz-se necessário, antes de adquirir qualquer arte ou habilidade que a pessoa receba instruções de um mestre, cabendo a este dizer o que deve ser feito, como deve ser feito e a melhor maneira de se fazer (1119b 11-19). A partir daí, com a prática advinda da repetição, nos tornamos bons e habilidosos; esta habilidade adquirida pela prática torna-se então uma espécie de segunda natureza. Uma criança pode herdar inteligência dos pais, mas apenas com a experiência (empeiria) e a repetição dos bons hábitos é que desenvolverá um bom caráter.

Em EN 1104b 11-14, Aristóteles recorda Platão e afirma que o treinamento correto dispensa a coerção, pois a pessoa devidamente treinada passa a ter prazer em fazer as coisas da maneira certa e da mesma forma, demonstrará angústia ao fazer as coisas de maneira equivocada. Entretanto, o ser humano não é bom ou mau por natureza, é apenas por habituação que somos feitos bons e é esta a disposição de caráter do homem bom e que o faz realizar bem a sua função. Assim Aristóteles afirma na Política 1255b 1-4:

As pessoas pensam que as boas pessoas provêm das boas pessoas, do mesmo modo que o humano vem do humano, e a besta da besta. Mas enquanto a natureza deseja fazer isto, ela é seguidamente incapaz de fazê-lo. (REEVE, 1998)

O caráter, aquilo que podemos considerar como os traços duradouros de uma pessoa que se expressam nas atitudes, sensibilidades, crenças, enfim no comportamento do indivíduo, inserido na sociedade e que influencia a sua maneira de agir e viver é tema que demandou muita investigação; o filósofo se preocupou principalmente com o bom caráter, ou seja, com aquele tipo dotado de virtudes que servem de guia para uma vida boa. Ao longo de quatro livros da Ethica Nicomachea, Aristóteles empreende uma abordagem minuciosa das excelências éticas; a discussão gira em torno de virtudes como a coragem, justiça, generosidade e outras que compartilham desejos, emoções, sentimentos e ações. Por exemplo, a coragem revela sentimentos humanos relacionados ao perigo como o medo, a confiança, a incerteza; a liberalidade ou generosidade diz 
respeito à relação com o dinheiro e assim nos livros II a V, Aristóteles analisa detidamente ações humanas virtuosas e viciosas.

Aristóteles entende a virtude do caráter como uma disposição da capacidade humana para sentimentos, desejos e ações, ou aquilo que ele chama de hexis, mostrando que a virtude é uma disposição desse tipo. Na passagem da EN II 5 1106a 15-24, ele dá o exemplo do olho humano, dizendo que a excelência do olho permite ao homem enxergar bem e com isso ele desempenha bem a sua função. Mas nem toda disposição é virtude, por exemplo, a irascibilidade ou irritabilidade é uma disposição ruim relacionada a sentimentos de raiva, que causa na pessoa que sente uma reação excessiva a insultos provenientes de uma provocação menor (1126a 14-31); a prodigalidade é uma má disposição relacionada ao dinheiro, uma pessoa servil apresenta comportamento subserviente na hora de ganhar dinheiro (1121b 31-4), enquanto o pródigo não economiza e gasta em excesso nas coisas erradas (1120b 20-5, 1107b 11-14). Aristóteles analisa disposições (hexeis) de caráter firmes e imutáveis (1105a 33, 1114 a 13-18).

A virtude do caráter é a responsável por uma inclinação no agente para que ele tenha sentimentos e desejos adequados, permitindo que ele faça escolhas apropriadas no momento da ação. Ao contrário, um vício do caráter é uma má disposição que inviabiliza o agir correto. É necessário entender a diferença entre virtude do caráter (ethike arete) e virtude intelectual (dianoetike arete) e como elas são interdependentes. As virtudes do caráter, enquanto elas são adquiridas por habituação, elas são mais que hábitos. Neste ponto a palavra inglesa 'state' contribui, porque as virtudes do caráter são os 'estados' permanentes ou a disposição firme e duradoura produzida pelo hábito.

Na Ethica Eudemia (EE 1220a 39) e na Ethica Nicomachea (EN 1103a 17), a virtude do caráter, pode ser pensada como um estado (hexis) criado em nossa vida psicológica (alma) ao longo do tempo, realizando repetidamente boas ações. Não há, porém, uma lista oficial de virtudes do caráter - Aristóteles relaciona algumas delas, como a temperança, a coragem e a justiça. A virtude do caráter refere-se ao estado de caráter e não às ações propriamente ditas; é indispensável que o sujeito passe pelo processo que podemos denominar como "aprendendo a ser bom".

O ponto crucial para entender sobre as virtudes do caráter é que elas são primariamente estados psicológicos criados por ações habituais. Quando os filósofos gregos falam de virtudes de caráter -justiça ou coragem, por exemplo - geralmente não estão falando de ações justas ou corajosas; eles estão falando sobre estados de caráter que consideram justos ou corajosos. As 
ações podem ser justas ou corajosas, mas nenhuma ação por si só pode ser chamada de ato de justiça ou de coragem, simplesmente porque parece um ato de justiça ou de coragem. Ações que parecem justiça ou coragem, mas que são realizadas pela razão errada ou que são tolas nas circunstâncias, não são realmente ações virtuosas. (DEVETTERE, 2002, p. 67)

A virtude moral, afirma Aristóteles, não é nem um sentimento nem uma capacidade, mas expressa um estado ou disposição (hexis) para agir ou sentir de certa maneira em determinadas circunstâncias, assim ele diz em EN II 5 1106a 12-14. O filósofo quando fala sobre a maneira pela qual se adquire a virtude moral, afirma que isso só é possível realizando uma ação correta repetidas vezes. Ele usa como exemplo, a aquisição da coragem, afirmando que é o hábito de desprezar e arrostar coisas terríveis que faz o homem se tornar bravo. Agir corretamente é crucial para a aprendizagem moral, logo a ação correta é de fundamental importância para os aprendizes morais (1105b 5-11).

A ação virtuosa depende de um estado ou disposição de caráter firme e imutável, isto nos faz crer que num primeiro estágio de aquisição de virtude o que se dá é simplesmente uma espécie de seguindo-o-exemplo-de-virtude. Durante todo o processo de educação do caráter, o aprendiz moral está sendo forjado e treinado nos bons hábitos. 
Somente quando o aprendiz adquire uma boa disposição (hexis) moral é que a virtude se manifesta como uma segunda natureza; provavelmente passa a fazer parte do agente moral e desta forma o homem não conseguirá jamais livrar-se dela.

Para Aristóteles, a virtude é essa disposição de caráter que nos torna capazes de agir tendo em vista o bem e ela está no próprio homem, é um princípio, nada é anterior a virtude no sentido de embasá-la. Na Ethica Eudemia 1220a 5-12, o filósofo explica que a virtude do caráter habilita a parte irracional da alma, que ao ser transformada pelo bom hábito, segue a razão e desta maneira podemos identificar alguém como gentil ou corajoso (INWOOD/WOOLF, 2013). Aristóteles prossegue na mesma passagem dizendo que, uma vez que as virtudes do pensamento são acompanhadas pela razão, estas pertencem à parte racional da alma, mas as virtudes do caráter localizam-se na parte irracional que por natureza segue e obedece à parte que tem razão. As virtudes morais são louváveis, por isso dizemos que um homem é gentil ou corajoso e não que ele é inteligente ou especialista em algum assunto.

Na Magna Moralia 1185b 5-10, Aristóteles diz que na parte racional da alma residem a sabedoria, a inteligência, a filosofia e a aptidão para o aprendizado, mas é na parte irracional que se encontram as virtudes, como por exemplo, a temperança, a justiça, a coragem e outras disposições morais pelas quais somos considerados louváveis; ele afirma mais uma vez que ninguém é louvado pelas virtudes da parte racional da alma (ROSS, 1915).

No livro VII da Política, Aristóteles explica o método que deve ser aplicado à educação do caráter; ele inicia sua explicação, afirmando que o tipo de alimentação que é dada às crianças quando nascem será determinante para o desenvolvimento de seus corpos e dá como exemplo a preocupação das nações em preparar as crianças para uma futura disposição militar incluindo na alimentação infantil muito leite e muito pouco vinho. Comenta também sobre os benefícios de exercícios físicos aplicados na idade correta e até incentiva que as crianças sejam habituadas desde tenra idade ao frio já que isso é muito útil tanto do ponto de vista da saúde quanto dos assuntos militares. Aristóteles afirma ser importante a orientação das crianças em tenra idade; nesta primeira fase da vida, é benéfico adotar algum tipo de supervisão. O filósofo prossegue sua argumentação e fala da importância da criação do hábito em 1336a 17-18. Ele diz nesta passagem, que sempre que for possível criar hábitos, que seja desde cedo e gradualmente, assim desta forma o corpo humano que é naturalmente quente deve ser treinado para suportar o frio desde a infância - os corpos das crianças são naturalmente 
adequados a este tipo de treinamento. Ao longo do capítulo 17 afirma que, mesmo a criança que está em fase de crescimento, é necessário que se exercite o suficiente para evitar a preguiça física e que isto deve ser feito através de brincadeiras e atividades lúdicas. Os jogos oferecidos às crianças pequenas não devem ser impróprios para pessoas livres ou indisciplinados e ainda devem imitar as ocupações sérias da vida adulta. As histórias e fábulas que podem ser contadas às crianças pequenas, devem ser tais que sirvam de orientação para as suas atividades posteriores. Aristóteles defende que até os sete anos de idade as crianças devem ser educadas no lar. Além disso, às pessoas mais jovens nem todas as coisas são permitidas, "[...] até que tenham atingido a idade de 20 anos, quando é apropriado reclinar-se na mesa comunal e beber vinho, e sua educação os tornou imunes ao mal que tais coisas podem causar.” (1336b 20-23)

Aristóteles explica em detalhes como deve ser a educação das crianças para que se tornem habituadas no bem, por conseguinte, futuros homens virtuosos. De acordo com o seu método, as crianças à princípio aprendem por imitação (mimesis); a educação do caráter, que obrigatoriamente deve começar na infância, num primeiro estágio deve ser feita em casa (Poética, 1448b 4-8).

Pois como nas cidades as leis e os tipos predominantes de caráter têm força, também nos lares fazem as injunções e os hábitos do pai, e estes têm ainda mais por causa do laço de sangue e dos benefícios que ele confere; pois as crianças começam com uma afeição natural e disposição para obedecer. Além disso, a educação individual tem uma vantagem sobre a comunidade, como o tratamento médico individual tem; pois enquanto em geral o descanso e a abstinência da comida são bons para um homem com febre, para um homem em particular eles podem não ser. (EN X 9 1180b 3-8)

A educação inicial prévia e mais tarde o treinamento pela habituação são necessários para executar certos elementos da tarefa de qualquer capacidade ou ofício. Portanto, fica evidente que isso também vale para as atividades que buscam desenvolver a virtude do caráter (Política 1337a 18-20). Aristóteles esclarece melhor este ponto em outra passagem (1336b 33-41), onde argumenta que tudo de ruim ou vulgar deve ser estranho aos jovens, principalmente se envolver vício ou malícia.

As crianças dos cinco aos sete anos de idade devem ser observadoras das lições que eventualmente terão que aprender - o aprendizado neste estágio, portanto, se realiza por imitação a partir de observações práticas. Na sequência ele explica que a educação dos jovens deve ser dividida em períodos de sete anos, estes são dois estágios que 
devem ser distinguidos, dos sete anos até a puberdade e da puberdade aos vinte e um anos. Aristóteles defende o emprego de diferentes métodos de aprendizagem a depender da faixa etária dos jovens nesta primeira fase da educação do caráter.

Na Política 1337a 1-2, Aristóteles apresenta a ideia que a arte e a educação procuram completar as carências da natureza; questiona ainda qual o tipo de organização deveria ser estabelecida para a educação das crianças, se as crianças deveriam ter o aprendizado supervisionado pela comunidade ou seria mais benéfico se feito em casa e que tipo de supervisão deveria ser esta. É o conhecimento das regras, dos métodos e das práticas que permite ao homem intervir no mundo para criar e produzir, ou seja, o que Aristóteles considera o 'fazer'. O filósofo diz que o legislador deve fazer o correto para enraizar as virtudes na alma dos homens e fazer cidadãos virtuosos por hábito, modificando seus costumes; assim da mesma forma, a educação faz dos cidadãos, homens de bem e põe as crianças no caminho certo (1103b 1-10).

O livro VI da Ethica Nicomachea confirma o pensamento de Aristóteles sobre a educação dos jovens que deve ser feita nos mesmos moldes daquele apresentado na Política. Mais que na sua obra Ethica Nicomachea, é na Política que Aristóteles revela a sua grande preocupação com a educação. São várias as questões apresentadas sobre o tema; o filósofo sabia que existiam enormes divergências no pensamento grego sobre a educação dos jovens; nem todos consideravam que os jovens deveriam aprender as mesmas coisas para promover a virtude ou a melhor vida. "A investigação da educação que vemos ao nosso redor resulta em confusão", diz Aristóteles (1337a 39). Menos evidente ainda era se a educação seria o meio mais apropriado para desenvolver a mente ou o caráter; mas a resposta de Aristóteles ao problema é de que a educação deve desenvolver ambas (1323b 1-3). O filósofo reconhecia não haver acordo sobre o que seria mais apropriado para promover a virtude e isso ele considerava simples de explicar, como nem todas as pessoas possuíam as mesmas virtudes, então compreensivelmente não concordavam com o treinamento necessário para adquirí-las. Entretanto Aristóteles se dedicou bastante ao tema e detinha opiniões firmes a esse respeito: "Desde então é evidente que a educação através da habituação deve vir antes da educação pela razão.” (1338b 3-4)

No campo do aprendizado, o filósofo apresenta uma proposta educacional bastante abrangente e na sua concepção, os jovens devem aprender a leitura e escrita, 
ginástica, música e até desenho; com relação à ginástica, por exemplo, Aristóteles diz que ela contribui para a coragem (1337b 25-27).

A visão ética de Aristóteles envolve o seu modo de conceber a política. Ética e política estão intrinsecamente relacionadas na medida em que tratam de postular a obtenção da virtude. Para o pensamento aristotélico a condição para um Estado ser feliz, exige que se mantenha nele a virtude e a prudência. Ética e política são práticas, ou seja, se definem pela ação; o agir ético é que torna possível a obtenção da virtude. O homem virtuoso é formado com a habituação na prática de ações virtuosas; essa ética é adquirida num primeiro momento no interior da família, o que é de fundamental importância e depois na cidade-estado - que cria as leis tendo em vista o bem comum e a educação correta dos cidadãos. $O$ legislador deve se preocupar com $o$ desenvolvimento da virtude no homem, isto tendo em vista uma vida em sociedade a melhor possível (1332a 34-37).

A virtude do caráter pressupõe a virtude moral cristalizada na alma humana. Portanto, a educação é a porta de entrada para as virtudes éticas; no que se refere à infância, a educação moral se dá com a criança recebendo uma boa orientação de seu tutor, com a inculcação de bons hábitos, preparando-a para desenvolver bem as atividades que mais tarde incumbem ao adulto. Aristóteles diz em EN 1103b 23-25: "Não faz pouca diferença, então, se formamos hábitos de um tipo ou de outro desde muito jovem; faz uma diferença muito grande, ou melhor, toda a diferença."

Para Antoine Hourdakis, Aristóteles poderia ser caracterizado como o médico da educação, aquele que sente a necessidade de formular uma teoria de caráter reformador e fisiopedagógico, de maneira metódica e em profundidade, permanecendo mais realista do que seu mestre Platão. O autor utiliza a expressão 'homem cultivado' para apresentar uma noção de homem com base em sua participação política, sua personalidade moral e capacidade criadora e ainda examinar a noção de educação como uma progressão deste ser humano desde o estado natural até atingir o raciocínio, passando pelo hábito conforme Aristóteles idealizou.

O conhecimento da virtude, por si só, não é suficiente para determinar o comportamento do homem. É preciso exercício e esforços laboriosos para se chegar lá. Assim, a virtude, associada às noções do fazer e do agir, torna-se uma das noções mais fundamentais da educação no âmbito de uma pedagogia ativa, que ainda hoje constitui o objetivo principal da reflexão pedagógica moderna. (HOURDAKIS, 2001, p. 11) 
Aristóteles reconhece que o homem precisa de 'adestramento' e a partir daí supera o seu mestre Platão ao desenvolver um método de educação fundado na práxis. No livro X da EN, o filósofo aborda a questão da força dos argumentos que se mostram insuficientes em si mesmos para tornar os homens bons. Aristóteles não crê no poder das palavras para incutir a nobreza e a bondade na multidão e defende que o homem comum não obedece à moralidade naturalmente e somente pode ser coagido pelo temor. Ele afirma em 1179b 16-17 que: "É difícil, se não impossível, remover por argumentação os traços que há muito foram incorporados ao caráter."

A partir destas considerações é possível verificar a importância de submeter o homem ainda jovem à educação do caráter adotando a habituação como método, ou seja, a repetição das ações corretas até que este hábito se incorpore na personalidade do agente, criando uma disposição de caráter moralmente virtuosa. Aristóteles considera indispensável à existência no homem de um caráter que tenha afinidade com a virtude, caso contrário todo aquele dirigido pelas paixões não poderá ser dissuadido pelos argumentos.

É por isso que alguns pensam que os legisladores devem estimular os homens à virtude e estimulá-los pelo motivo dos nobres, partindo do pressuposto de que aqueles que estiverem bem adiantados pela formação de hábitos responderão a tais influências; e que punições e penalidades devem ser impostas àqueles que desobedecem e são de natureza inferior, enquanto que o incuravelmente ruim deve ser completamente banido. Um homem bom (eles pensam), uma vez que ele vive com a mente fixa no que é nobre, submeter-se-á ao argumento, enquanto um homem mau, cujo desejo é por prazer, é corrigido pela dor como um animal de carga (1180a 6-12). 
Moss considera que o prazer é percebido naturalmente na realização das atividades de uma pessoa com excelência ética.

[...] o prazer perceptivo é o que surge quando, com os sentidos em bom estado, percebemos objetos excelentes; o prazer intelectual é o que surge quando, com o intelecto em bom estado, consideramos objetos excelentes. Por isso, o prazer é, por sua própria natureza, conectado à percepção de algo bom. (MOSS, 2012, p.31)

Mas como se dá essa habituação capaz de desenvolver uma disposição de caráter que transformará o ser humano in natura em uma pessoa virtuosa? A aprendizagem moral se dá gradativamente, o aprendiz deve ser treinado naquilo que é justo e bom; o candidato a agente virtuoso ganha experiência enquanto recebe boas instruções. E somente mais tarde, o aprendiz poderá utilizar sua capacidade racional para fazer independentemente suas escolhas e agir virtuosamente. Aristóteles afirma que a disposição de caráter virtuoso, ou seja, o estado bom e firme devotado ao bem é uma construção feita com base na repetição de ações corretas (1144a 15-20 ).

A experiência relevante, insiste Aristóteles, é a de realmente se engajar nas atividades da disciplina prática. No caso do médico, isso significa envolver-se na prática clínica. No caso do navegador, isso significa passar um tempo no mar. No caso da pessoa que quer viver bem, isso envolve muita prática em engajar-se no negócio da vida: lidar com outras pessoas, com os apetites e com os medos, para citar apenas alguns. É desse tipo de experiência que se adquire o conhecimento intelectual excelente (phronesis) que nos permite apreender e responder apropriadamente às particularidades das situações que a vida nos traz. (MEYER, 2008, p.82)

Na Poética, Aristóteles aborda a questão do homem virtuoso e afirma que a tragédia imita a ação e cada personagem se apresenta de acordo com o seu caráter e pensamento; é o caráter e o pensamento do homem que qualificam suas ações, portanto são estes que determinam a boa ou a má fortuna dos homens (1449b 35-1450a 4). Aqueles que aprendem um assunto pela primeira vez conectam-se às proposições de maneira ordenada, mas ainda não as conhecem; as proposições precisam antes de qualquer coisa se tornar uma segunda natureza e isso leva tempo.

Essa segunda natureza, característica de um caráter firme e imutável, é a causa de uma espécie de 'familiaridade'. Mais tarde é preciso que o aprendiz entenda o 'porquê', o único capaz de realizar a correção final e o aperfeiçoamento de sua percepção de 'o que'. Uma coisa é aprender a fazer o que é justo e outra completamente 
diferente de se aprender é porque é justo. Por isso o treinamento moral antecede o treinamento do intelecto e neste primeiro estágio aprende-se por imitação, ou seja, seguindo bons exemplos e habituando-se nos bons hábitos.

A ideia de imitação e de mimesis é o centro da análise estética de Aristóteles; supondo - pelo conceito - uma associação entre o que é apresentado ou representado e a existência prévia da pessoa: espectador ou aprendiz. A noção do imitar tem a ver com a perspectiva da preservação: imita-se o que se louva; louva-se o que é honrado, e, portanto, o que deve ser preservado. Na educação, como na dramaturgia, o criador convida o espectador a se envolver com um desempenho, uma mimesis da realidade, e, portanto, por delegação, com a própria realidade. (MCLEISH, 2000, p.18).

A imitação faz parte da natureza do homem que desde a infância observa e segue os passos daqueles que admira; o homem é diferente dos outros animais, na medida em que é extremamente imitativo e faz seus primeiros passos no aprendizado por meio da imitação. Aristóteles reconhece a força da imitação (mimesis) como elemento fundador da vida social e, mais especificamente, como instrumento para viabilizar a educação moral através do ensino e dos bons hábitos. A mimesis é capaz de produzir dois resultados simultaneamente, conforme o filósofo expõe na Poética (1448b 4-8), a mimesis instrui e ao mesmo tempo dá prazer. Os seres humanos são naturalmente curiosos e gostam de aprender por meios miméticos. É por isso que a mimesis é uma prática distintamente humana. A atividade imitativa é natural nos seres humanos (1448b 20): temos prazer em aprender, e aprendemos através da mimesis, então nós naturalmente temos prazer na imitação.

\section{Conclusão:}

Aristóteles trabalhou as questões éticas numa espécie de simbiose com as questões educativas. Foi ele quem percebeu a necessidade de desenvolver um método que pudesse criar a virtude no homem na prática. Trata-se de aprender a agir corretamente nas diversas situações da vida através da habituação, ou seja, com a prática. Aristóteles logo percebeu que, para saber como agir, precisamos ser treinados nos bons hábitos e que não basta conhecimento intelectual do que é bom e desse modo, a ética une-se à educação. Na Política, e em suas obras éticas, aprende-se que a ética e a política de Aristóteles convertem-se em educação para o agir correto, para a formação do caráter moral do jovem e desenvolvimento das virtudes. O vínculo entre ética e educação é essencial. Além da educação tradicional de "leitura dos poetas, música, ginástica", 
vimos que é preciso adestrar nossos desejos se estes forem insensatos ou injustos. Não se trata apenas de ter a motivação moral para agir com vistas a uma utilização prática imediata, mas o alvo a alcançar é consolidar uma boa motivação por toda a vida para o agir correto.

\section{Referências:}

ANGIONI, Lucas. Aristóteles Ética a Nicômaco Livro VI. Dissertatio. Pelotas, V.34, pp. 285-300, 2011. https://doi.org/10.15210/dissertatio.v34i0.8705

BURNYEAT, M.F. Explorations in ancient and modern philosophy volume II. First Ed.

New York: Cambridge University Press, 2012.
https://doi.org/10.1017/CBO9780511974052

DEVETTERE, R. J. Introduction to Virtue Ethics. Insights of the Ancient Greeks. Washington, D.C.: Georgetown University Press, 2002.

HOURDAKIS, Antoine. Aristóteles e a Educação. São Paulo: Edições Loyola, 2001.

INWOOD, B. \& WOOLF, R. Aristotle. Eudemian Ethics. New York: Cambridge University Press, 2013. https://doi.org/10.1017/CBO9781139043281

KRISTJÁNSSON, K. Aristotle, emotions and education. England: Ashgate Publishing Limited, 2007.

LORENZ, H. Virtue of Character in Aristotle's Nicomachean Ethics. Oxford Studies in Ancient Philosophy, Vol. XXXVII, 2009.

MCLAUGHLIN, T.H. \& HALSTEAD, J.M. Education in character and virtue. In Education in morality. New York: Routledge, 2005.

MCLEISH, K. Aristóteles: A poética de Aristóteles. Trad. de Raul Fiker. São Paulo: UNESP, 2000.

MEYER, Susan Sauvé. Ancient ethics: a critical introduction. New York: Routledge Taylor \& Francis Group, 2008.

MOSS, Jessica. "Virtue Makes the Goal Right": Virtue and Phronesis in Aristotle's Ethics. Phronesis. NY: V.56, 2011. https://doi.org/10.1163/156852811X575907

MOSS, Jessica. Aristotle on the Apparent Good Perception, Phantasia, Thought, and Desire. UK: Oxford University 2012. https://doi.org/10.1093/acprof:oso/9780199656349.001.0001

REEVE, C.D.C. Aristotle. Politics. Indianápolis: Hackett Publishing Company, 1998.

ROSS \& BROWN. Aristotle. [Nicomachean Ethics. English] The Nicomachean Ethics/Aristotle; translated by David Ross; revised with an introduction and notes by Lesley Brown. Oxford University Press Inc., New York, 2009. 
Revista Primordium v.3 n.5 jan./jul. - .2018 ISSN: 2526-2106

http://www.seer.ufu.br/index.php/primordium

ROSS, D. The works of Aristotle. Oxford: Oxford University Press, 1915.

Data de registro: $12 / 11 / 2018$

Data de aceite: 13/02/2019 